\title{
Selenium Increases Fruit Quality By Reducing Ethylene Production And The Stone Cell Content In Pear (Pyrus Ussuriensis)
}

\section{Chi Yuan}

Shenyang Agricultural University

Haidong Bu

Shenyang Agricultural University

Jiaming Zhao

Shenyang Agricultural University

Jiaojiao Liu

Shenyang Agricultural University

Hui Yuan ( $\nabla$ huiyuan@syau.edu.cn )

Shenyang Agricultural University

Aide Wang

Shenyang Agricultural University

\section{Research Article}

Keywords: pear, Selenium, fruit quality, ethylene, stone cell

Posted Date: June 29th, 2021

DOI: https://doi.org/10.21203/rs.3.rs-626936/v1

License: () (1) This work is licensed under a Creative Commons Attribution 4.0 International License.

Read Full License 


\section{Abstract}

Background:Selenium (Se) is an essential trace element for both animals and plants. Se treatment can increase fruit Se concentration and shelf life. However, the mechanism underlying Se-delayed fruit ripening is still unclear.

Results:In this research, two groups of Se (A and B treatments) were used to treat 'Nanhong' pear fruit. The results showed that these treatments could greatly increase the Se content but decreased the titratable acid content. Treatment A significantly decreased ethylene production, and the key genes controlling ethylene production, PUACSS and PUERF2, were inhibited by Se treatment. In addition, treatment A significantly decreased the stone cell content, and one lignin biosynthesis gene, $\mathrm{PuC} 4 \mathrm{H}$, was downregulated by treatment $A$.

Concusions:Se treatment increased the Se content in pear fruit. In addition, Se decreased ethylene production and the stone cell content. Moreover, the key genes for ethylene production (PuACSs and PuERF2) and lignin biosynthesis (PuC4H) were also inhibited by Se treatment.

\section{Background}

Selenium (Se) is an essential trace element for both animals and plants; however, Se deficiency in the diet is now a global problem [1]. About one billion people worldwide suffer from Se deficiency [2], including those in many areas in China [3]. Se deficiency in the human body may be related to some serious medical complications, such as hypothyroidism [4], cataracts, cardiomyopathy, and even cancer [5-6]. Diets are the major Se source for humans, but the Se contents in staple food are very low and are unable to meet the requirement for health [7]. Therefore, biofortification of Se-enriched food is very important for increasing the Se concentration in food and will be helpful for human health [8]. Foliar spraying and soil application are both effective means to increase the Se content in food, and the latter is much more effective [9].

In plants, low and moderate Se concentrations can promote growth and ameliorate the adverse effects of environmental stresses [10-11], such as drought [12], water [13], and salt [14]. Se can alleviate Cdinhibited plant growth in cucumber [15]. Se is also able to decrease the production of ethylene and phenylalanine ammonia lyase (PAL) activity, prolonging the shelf life of both lettuce and chicory [16]. There has been a recent interest in the effects of Se on fruit physiology. For example, Se makes tomato fruit more resistant to postharvest decay and increases the concentration of non-enzymatic antioxidants $[1,11]$. Se can decrease the rate of ethylene biosynthesis in tomato, leading to a delay in fruit ripening [17]. Foliar Se treatment can decrease ethylene production by repressing the expression of ACS and ACO in tomato fruit [18]. Se treatment can increase the Se concentration in fruit and prolong the shelf life by delaying the reduction of flesh firmness and fruit ripening in peach and pear [19]; however, the mechanism of how Se delays fruit ripening is still unclear. 
'Nanhong' pear (Pyrus ussuriensis) is a red bud sport variety of 'Nanguo' pear. The fruit of 'Nanhong' pear is typical climacteric fruit, and ethylene is the main factor controlling the ripening process [20]. During ripening, the fruits produce high amounts of ethylene, and firmness drops rapidly. 'Nanhong' pear fruits have exhibited poor quality in recent years, such as a rapid increase in the stone cell content and a decrease in the aroma, which seriously influence the shelf life and economic benefits of 'Nanhong' pear. Thus, finding a way to improve fruit quality is very important for 'Nanhong' pear. As an important trace element, Se is increasingly used for vegetables, fruits, and food crops to produce selenium-rich foods [21]. However, little known about whether Se treatment can increase the Se content and fruit quality of 'Nanhong' pear.

Here, we used Se to treat 'Nanhong' pear and found that the Se content increased in the Se-treated fruits. In addition, both the ethylene production and the stone cell content decreased. Our results showed that Se treatment can improve the quality of 'Nanhong' pear fruit, which provides new insights for fruit quality and will be helpful for the industrial growth of 'Nanhong' pear.

\section{Results}

\section{The Se content increases in treated pear}

The Se dietary allowance for adults is 55-75 ug/day, and Se deficiency in the diet is now a global problem [22]. In order to clarify whether the application of exogenous Se could increase the Se content in 'Nanhong' pear, we treated 'Nanhong' pear during fruit development. The results indicated that the pear skin treated by Se was much smoother than untreated pear skin (Figure 1A). We then measured the Se content in treated fruits, finding that both treatments $A$ and $B$ greatly increased the Se content in these fruits (Figure 1B). These results indicated that our treatments were effective and suitable for the following research.

\section{Effect of Se on fruit storage quality}

Storage quality is one of the most important economic traits of fruits; a good storage quality has a decisive influence on the fruit quality and market value. In order to detect the effect of Se on fruit storage quality, we measured the ethylene production and hardness of the fruits under Se treatment. The results showed that both treatments increased fruit hardness during storage, especially on 10 and $15 \mathrm{DAH}$ (Figure 2A). The ethylene production was inhibited by these two treatments, especially treatment $A$ (Figure 2B).

\section{Effect of Se on fruit sensory quality}

'Nanhong' pear fruits have an appealing color, with soft flesh, and are full of juice, but they also have large amounts of stone cells, which greatly influence fruit quality. In order to clarify the influence of Se treatment on the stone cell content, we measured the stone cell content of the pears treated with Se during fruit storage. Because the fruits on $15 \mathrm{DAH}$ were too soft, we only present the results for 0,5 , and 
$10 \mathrm{DAH}$. On 0 and $5 \mathrm{DAH}$, both treatments decreased the stone cell content. On $10 \mathrm{DAH}$, treatment $\mathrm{A}$ decreased the stone cell content whereas $\mathrm{B}$ had the opposite effect (Figure $3 \mathrm{~A}$ ).

We then analyzed the soluble acid content and found that the soluble acid content continued to increase as the storage time prolonged, with no significant difference between the control and treatments (Figure 3B). Soluble acid includes sugar, titratable acid, and other components, so we measured the titratable acid content. Both treatments $A$ and $B$ greatly decreased the titratable acid content (Figure $3 C$ ), leading to an increase in the solidity-acid ratio (Figure 3D). We believed that treatment $A$ was much more effective than treatment $B$, so we chose treatment $A$ for the following research.

We measured the soluble sugar content in the treatment and control. Glucose, fructose, and sorbitol increased in response to Se treatment, but no significant difference was observed for sucrose (Figure 4).

\section{Effect of Se on expression patterns of ethylene biosynthesis and signal transduction genes}

Treatment A inhibited ethylene production (Figure 2B), so we analyzed the expressions of PuACS1 and PUACS4, which are key enzymes in pear ethylene biosynthesis [20], and we found that the expressions of PUACS1 and PUACS4 were inhibited by Se treatment (Figure 5A and B), showing a similar tendency as that observed for ethylene (Figure 2B).

ERF is a key transcription factor in the ethylene signal transduction pathway [23]. PuERF2 was proved to play an important role in pear ethylene signal transduction [24], and our result showed that the expression of PUERF2 was greatly inhibited by Se treatment (Figure 5C). Therefore, we speculated that Se might inhibit ethylene production by inhibiting the expression of PUERF2, which regulates the expression of PUACS1 and PUACS4.

\section{Effect of Se on the expression patterns of lignin-related genes}

Lignin is the precursor of stone cells [25], and Se decreased the stone cell content in pear (Figure 3A). We examined the expressions of the COMT (caffeic acid 3-0-methyltransferase), $\mathrm{C} 4 \mathrm{H}$ (cinnamate-4-hydroxylase), and $C A D$ (cinnamyl alcohol dehydrogenase) genes, which are important for lignin biosynthesis. The expression of PUCOMT decreased during fruit storage, but it was not inhibited by Se treatment (Figure 6A). The expression pattern of PuCAD was not regular (Figure 6B). PuC4H was greatly inhibited by Se treatment, especially on 10 and $15 \mathrm{DAH}$ (Figure 6C), indicating that $\mathrm{PuC} 4 \mathrm{H}$ may be the key gene responsible for stone cell reduction in Se treatment.

\section{Discussion}

Se is indispensable for life, and a moderate Se concentration is beneficial to both animals and plants [11]. However, hyper-accumulated levels of Se are toxic to the creatures mentioned above. For adults, the Se dietary allowance is $55-75 \mu \mathrm{g} /$ day [22], whereas a toxic critical concentration is $400 \mu \mathrm{g} / \mathrm{day}$ [26]. Through Se treatment, the Se concentration in 'Nanhong' pear fruit was approximately $40-60 \mu \mathrm{g} / \mathrm{kg}$ (Fig. 1B), and the average weight of 'Nanhong' pear fruit used in this research was about $100 \mathrm{~g}$, indicating 
approximately 4-6 $\mu \mathrm{g}$ Se in each treated fruit. Therefore, our method used here to produce Se-biofortified pear fruit is available and safe for humans.

Se treatment decreased the biosynthetic rate of ethylene in red tomato fruits [17] and could increase fruit firmness in peach and pear [19]. The present study showed that Se treatment inhibited ethylene production during the pear storage period (Fig. 2B), which is in agreement with the results mentioned above. ACS (ACC synthase) is the rate-limiting enzyme in ethylene biosynthesis [27], and PUACS1 and PUACS4 are the main ACS genes controlling ethylene production in 'Nanguo' pear, similar to 'Nanhong' pear. Here, for the first time, we showed that Se could inhibit the expression of PUACS1 and PUACS4 in pear (Fig. 5A and B), leading to ethylene reduction. This agrees with a previous study in which ACS2 and ACS4 were inhibited by Se treatment [18]. ERFs (ethylene response factors) are located in the downstream region of the ethylene signal transduction pathway and regulate the transcription of ethylene-responsive genes, including ACS genes. The expression of PUERF2 was induced by ethephon treatment and was thought to play an important role in 'Nanguo' pear fruit ripening [24]. Se treatment also inhibited the expression of PUERF2 (Fig. 5C), with an expression pattern similar to those of PUACS1 and PUACS4 (Fig. 5). Therefore, we speculated that PuERF2 could control ethylene production by regulating the expression of PUACS2 and PUACS4, and Se inhibited the expression of PUERF2, finally leading to a decrease in ethylene. However, further research is needed to determine how Se treatment regulates PUERF2 expression.

The stone cell content is very important for pear fruit and can influence the pear fruit quality, such as flesh hardness and chewiness [28]. Therefore, it is very important to lower the stone cell content in pear. $\mathrm{CaCl}_{2}$ treatment $(0.50 \%)$ reduced the stone cell distribution density in pear [29]. In addition, ethephon reduced the stone cell content in 'Korla fragrant pear' [30]. In the present study, we found that Se treatment reduced the stone cell content in pear fruit (Fig. 3A). Lignin is the main component of stone cells in pears [25]. Lignin biosynthesis is controlled by enzymes that participate in lignin monomer transport and polymerization [31], and $\mathrm{C} 4 \mathrm{H}$ is a key enzyme of lignin biosynthesis. Overexpression of $\mathrm{PbC4H} 1$ and $\mathrm{PbC4H} 3$ increased the lignin content of xylem cells in Arabidopsis [31]. When $\mathrm{C} 4 \mathrm{H}$ expression is inhibited, the total lignin content is significantly reduced [32]. The expression level of $\mathrm{GbC4H}$ was correlated with the lignin content in different tissues [33]. The expression of $C 4 H$ can be regulated by certain abiotic stresses and hormonal treatments. The $\mathrm{C} 4 \mathrm{H}$ gene in kenaf was induced by ABA treatment [34], similar to the result for $\mathrm{GbC4H}$ [33]. Low temperature can also induce the expression of $\mathrm{C} 4 \mathrm{H}$ genes, such as Rhododendron catawbiense RcC3H and Hibiscus cannabinus HcC4H [35-36]. Here for the first time, we showed that Se treatment inhibited the expression of PuC4H in pear (Fig. 6C). These results indicate that in addition to abiotic stresses and hormonal treatments, Se can also influence the expression of $\mathrm{C} 4 \mathrm{H}$. Therefore, we speculate that Se may reduce the stone cell content by inhibiting the expression of $\mathrm{PuC} 4 \mathrm{H}$. We will conduct further research to explore the mechanism in detail.

\section{Conclusion}


Se treatment increased the Se content in pear fruit. In addition, Se decreased ethylene production and the stone cell content. Moreover, the key genes for ethylene production (PuACSs and PuERF2) and lignin biosynthesis (PuC4H) were also inhibited by Se treatment.

\section{Methods}

\section{Plant materials and treatments}

'Nanhong' pear (Pyrus ussuriensis Maxim.) trees were grown at the experimental farm of Shenyang Agricultural University (Shenyang, China). We designed two treatments, and distilled water was used as a control. Treatment A was a 7000 -fold dilution of a mixture of $0.1 \%$ nano-selenium fertilizer (Hengshui Gemei Micronutrient Co., Ltd., Hengshui, China), 40\% ethephon (an ethylene precursor compound; Sigma, http://www.sigmaaldrich.com/), and a 1000-fold dilution of 1\% sodium selenite (10102-18-8, Nanjing Chemical Reagent Co., Ltd., Nanjing, China). Treatment B was a 5000 -fold dilution of a mixture of $0.1 \%$ nano-selenium fertilizer, $40 \%$ ethephon, and a 1000 -fold dilution of $1 \%$ sodium selenite. The treatments were used to spray the trees, including leaves and fruits, 60, 75, and 95 days after flowering. After harvest, the fruits were transported to the laboratory and stored at room temperature for 15 days; sampling was conducted every 5 days. At each sampling time, fruits were used to measure ethylene production and other indexes, and then the fruits were sliced, frozen in liquid nitrogen, and stored at $-80^{\circ} \mathrm{C}$ for later use.

\section{Measurement of fruit firmness}

The fruit firmness measurement was carried out according to Yuan et al [37] using a portable pressure tester (FT-327, Facchini, Italy) fitted with an 11-mm-diameter probe. Each fruit was cut into four thin discs (approximately $2.5 \mathrm{~cm}$ in diameter) from opposite sides. The probe was pressed into the cut surface of the fruit to a depth of 8-9 $\mathrm{mm}$. Five fruits were used per sample.

\section{Measurement of soluble solids and the sugar content}

For the measurement of soluble solids, the fruit flesh was ground into a powder and filtered through a cell strainer (Cat. no. CSS010040, Jet Biofil, https://www.jetbiofil.com), and then the soluble solids remaining on the filter were measured by a sugar meter (PAL-1, Atago, Tokyo, Japan). Measurement of the sugar content was carried out using an HPLC 1260 Infinity Series (Agilent Technologies, Santa Clara, CA, USA) according to Li et al [38]. First, one gram of each sample was placed in a $50 \mathrm{ml}$ centrifuge tube to which $10 \mathrm{ml} 80 \%(\mathrm{v} / \mathrm{v})$ ethanol was added. The sample was incubated at $80^{\circ} \mathrm{C}$ for $30 \mathrm{~min}$ and then centrifuged at $12000 \mathrm{rpm}$ for $5 \mathrm{~min}$. The supernatant was transferred into a new tube, and the above steps were repeated twice to ensure complete extraction. The supernatant was dried by distillation, and then $1 \mathrm{ml}$ distilled water was used to dissolve the sugar. The solution was passed through a $0.45 \mathrm{~mm}$ membrane, and then the soluble sugar content was measured by HPLC (Agilent 1260). The specific methods were as follows: 3 mm, $7.8 \times 300$ mm Carbomix Ca-NP column (Sepax Technologies, Inc., Newark, DE, USA); column temperature of $80^{\circ} \mathrm{C}$; refractive index detector temperature of $35^{\circ} \mathrm{C}$; and an injection volume of 10 
$\mathrm{ml}$. Nine fruits were collected at each sampling time and were randomly divided into three groups as three biological replicates.

\section{Measurement of ethylene production}

One or two fruits were enclosed in an airtight container $\left(0.86 \mathrm{I}, 24^{\circ} \mathrm{C}\right)$ equipped with septa, and $1 \mathrm{ml}$ gas was sampled using a syringe. The ethylene production was measured with a gas chromatograph (Agilent 7890A, Santa Clara, USA) according to Tan et al [39]. Five fruits per sample were measured.

\section{Measurement of the stone cell content}

The stone cell contents were measured using the hydrochloric acid treatment method according to Lee et al [40] with slight modification as follows: $10 \mathrm{~g}$ of each sample was mixed and diluted with distilled water. Solutions were allowed to settle for $30 \mathrm{~min}$, after which the supernatant was decanted; the above steps were repeated twice. The sediment was suspended in $0.5 \mathrm{M} / \mathrm{L} \mathrm{HCL}$ for 30 min, decanted and washed twice using distilled water. Finally, the sediment was dried in an oven at $65^{\circ} \mathrm{C}$, and the stone cell content was measured. Nine fruits were collected at each sampling time and were randomly divided into three groups as three biological replicates.

\section{Measurement of the titratable acid content}

An acid-base titration was used to measure the titratable acid content, with phenolphthalein as an indicator. Nine fruits were collected at each sampling time and were randomly divided into three groups as three biological replicates.

\section{Measurement of Se content}

The sample was soaked with nitric and perchloric acid (7:1) overnight, after boiled at $100{ }^{\circ} \mathrm{C}$ for $12 \mathrm{~h}$, digested at $150^{\circ} \mathrm{C}$ until the digests were clear and transparent. Then the digests were diluted with distilled water to $25 \mathrm{ml}$. Finally, the digests were analyzed by ICP-MS (Inbaictively coupled plasma mass spectrometry). Nine fruits were collected at each sample point, and were divided into three groups randomly as three biological replicates.

\section{Quantitative RT-PCR}

Total RNAs of each sample point were extracted according to Li et al [41], with little modification. One $\mu \mathrm{g}$ of total RNA was used to synthesize first-strand cDNA using a PrimeScript First Strand cDNA Synthesis Kit (Takara, Japan).

Quantitative RT-PCR (qRT-PCR) was performed as described by Bu et al [42]. The primers for each gene were designed by the online website Primer3 (http://primer3.ut.ee/) and were listed in supplementaly table1. Three replications were conducted. 


\section{Abbreviations}

ACS: ACC synthase

ACO: ACC oxidase

qRT-PCR: Quantitative RT-PCR

ERF: Ethylene response factors

PAL: Phenylalanine ammonia lyase

COMT: Caffeic acid 3-0-methyltransferase

C4H: Cinnamate-4-hydroxylase

CAD: Cinnamyl alcohol dehydrogenase

HPLC: High Performance Liquid Chromatography

ICP-MS: Inbaictively coupled plasma mass spectrometry

\section{Declarations}

\section{Ethics approval and consent to participate}

Not applicable.

\section{Consent for publication}

Not applicable.

\section{Availability of data and materials}

The datasets used and/or analysed during the current study are available from the corresponding author on reasonable request.

\section{Competing interests}

The authors declare that they have no competing interests.

\section{Funding}

This work was supported by the National Key R\&D Program of China (2018YFD0201403) and the National Natural Science Foundation of China (31801834). The funding bodies had no role in study design, collection, analysis and interpretation of data, or in writing the manuscript. 
Authors' contributions

A W conceived this project. CY performed most of the experiments. JZ and JL treated the sample. $\mathrm{HB}$ and HY wrote the manuscript. All authors have read and agreed to the published version of the manuscript.

\section{Acknowledegements}

Not applicable.

\section{References}

1. Schiavon M, Dall'Acqua S, Mietto A, Pilon-Smits E, Sambo P, Masi A, Malagoli M. Selenium fertilization alters the chemical composition and antioxidant constituents of tomato (solanum lycopersicon I.). J Agric Food Chem. 2013; 61(44): 10542-54.

2. Trippe RC, Pilon-Smits E. Selenium transport and metabolism in plants: Phytoremediation and biofortification im-plications. J Hazard Mater. 2021; 404:124178.

3. Dinh QT, Cui Z W, Huang J, Tran T T, Wang D, Yang W X, Zhou F, Wng MK, Yu DS, Liang DL. Seleni-um distribution in the Chinese environment and its relationship with human health: a review. Environ Int. 2018; 112:294-309.

4. Arthur JR, Nicol F, Beckett GJ. The role of selenium in thyroid hormone metabolism and effects of selenium defi-ciency on thyroid hormone and iodine metabolism. Biol Trace Elem Res. 1992; 33(13):37-42.

5. Natasha SM, Niazi NK, Khalid S, Murtaza B, Bibi I, Rashid MI. A critical review of selenium biogeochemical behavior in soil-plant system with an inference to human health. Environ Pollut. 2018; 234: 915-34.

6. Newman R, Waterland N, Moon Y, Tou JC. Selenium biofortification of agricultural crops and effects on plant nu-trients and bioactive compounds important for human health and disease prevention-a review. Plant Food Hum Nutr. 2019;74: 449-60.

7. Zhou X, Yang J, Kronzucker HJ, Shi W. Selenium Biofortification and Interaction With Other Elements in Plants: A Review. Front Plant Sci. 2020;11.

8. White PJ, Broadley MR. Biofortification of crops with seven mineral elements often lacking in human diets-iron, zinc, copper, calcium,magnesium, selenium and iodine. New Phytol. 2009; 182:49-84.

9. Deng XF, Zhao ZQ, Han ZY, Huang LQ, Liu XW. Selenium uptake and fruit quality of pear (Pyrus communis L.) treated with foliar Se application. J Plant Nutr Soil Sci. 2019;182:637-46.

10. Hamilton SJ. Review of selenium toxicity in the aquatic food chain. Sci Total Environ. 2004; 326:131.

11. Zhu Z, Chen Y, Zhang X, Li M. Effect of foliar treatment of sodium selenate on postharvest decay and quality of tomato fruits. Sci Hortic. 2016;198:304-10. 
12. Hasanuzzaman M, Fujita M. Selenium pretreatment upregulates the antioxidant defense and methylglyoxal detoxifi-cation system and confer enhanced tolerance to drought stress in rapeseed seedlings. Biol Trace Elem Res. 2011; 143(3):1758-76.

13. Wang C. Water-stress mitigation by selenium in Trifolium repens L. J Plant Nutr Soil Sci. 2011;174: 276-82.

14. Hasanuzzaman M, Hossain MA, Fujita M. Selenium-induced up-regulation of the antioxidant defense and methyl-glyoxal detoxification system reduces salinity-induced damage in rapeseed seedlings. Biol Trace Elem Res. 2011;143(3):1704-21.

15. Sun HY, Wang XY, Li HM, Bi JH, Yu J, Liu XJ, Zhou HX, Rong Z J. Selenium modulates cadmi-uminduced ultrastructural and metabolic changes in cucumber seedlings. RSC Adv. 2020; 10:17892.

16. Malorgio F, Diaz K, Ferrante A, Mensuali-Sodi A, Pezzarossa B. Effects of selenium addition on minimally pro-cessed leafy vegetables grown in floating system. J Sci Food Agric. 2009; 89(13):2243-51.

17. Pezzarossa B, Rosellini I, Borghesi E, Tonutti P, Malorgio F. Effects of Se-enrichment on yield, fruit composition and ripening of tomato (Solanum lycopersicum) plants grown in hydroponics. Sci Hortic. 2014;165: 106-10.

18. Zhu Z, Chen Y, Shi G, Zhang X. Selenium delays tomato fruit ripening by inhibiting ethylene biosynthesis and en-hancing the antioxidant defense system. Food Chem. 2017; 219: 179-84.

19. Pezzarossa B, Remorini D, Gentile M L, Massai R. Effects of foliar and fruit addition of sodium selenate on seleni-um accumulation and fruit quality. J Sci Food Agric. 2012; 92: 781-86.

20. Yuan H, Yue PT, Bu HD, Wang AD. Genome-wide analysis of ACO and ACS genes in pear (Pyrus ussuriensis). In Vitro Cell Dev Biol-Plant. 2019; 56:193-99.

21. Nawaz F, Ashraf MY, Ahmad R, EA Waraich, Shabbir RN, Hussain RA. Selenium Supply Methods and Time of Application Influence Spring Wheat (Triticum aestivum L.) Yield under Water Deficit Conditions. J Agric Sci. 2017;155(04): 643-56.

22. National Academy of Sciences. Dietary reference intakes for vitamin C, vitamin E, selenium, and carotenoids: a report of the Panel on Dietary Antioxidants and Related Compounds, Subcommittees on Upper Reference Levels of Nutrients and of Interpretation and Use of Dietary Reference Intakes. 2000.

23. Stepanova AN, Alonso JM. Ethylene signaling and response: where different regulatory modules meet. Curr Opin Plant Biol. 2009;12(5): 548-55.

24. Yue PT, Wang YN, Bu HD, Li XY, Yuan H, Wang AD. Ethylene promotes IAA reduction through PuERFsactivated PuGH3.1 during fruit ripening in pear (Pyrus ussuriensis). Postharvest Biol Technol. 2019;157: 110955.

25. Zhang JY, Li JM, Xue C, Wang RZ, Zhang MY, Qi KJ, Fan j, Hu HJ, Zhang SL, Wu J. The Variation of Stone Cell Content in 236 Germplasms of Sand Pear (Pyrus pyrifolia) and Identification of Related Candidate Genes. Hortic Plant J. 2021; 7(2):108-16.

26. Combs G. Selenium in global food systems. Br. J. Nutr. 2001;85: 517-47. 
27. Kende H. Ethylene biosynthesis. Annu Rev Plant Physiol Plant Mol Biol. 1993; 44: 283-307.

28. Zhang JY, Cheng X, Jin Q, Su XQ, Yan CC, Jiao XY, Li DH, Lin Y, Cai YP. Comparison of the transcriptomic analysis between two Chinese white pear (Pyrus bretschneideri Rehd.) genotypes of different stone cells contents. PLoS One. 2017;12(10): e0187114.

29. Tao ST, Khanizadeh S, Zhang H, Zhang SL. Anatomy, ultrastructure and lignin distribution of stone cells in two Pyrus species. Plant Sci. 2009; 176(3): 413-19.

30. Chen Y, Zhang Q, Dong YZ, Tao ST, Zhang TZ, Bao JP. Effects of ethephon on the rate of calyxabscission and fruit quality of 'Korla Fragrant Pear' and 'Xinli No.7'. J Henan Agric Univ. 2020;54(6):949-55.

31. Li GH, Liu X, Zhang Y, Muhammad A, Han WL, Li DH, Cheng X, Cai YP. Cloning and functional character-ization of two cinnamate 4-hydroxylase genes from Pyrus bretschneideri. Plant Physiol Biochem. 2020;156:135-45.

32. Sykes RW, Gjersing EL, Foutz K, Rottmann, WH, Kuhn SA, Foster CE, Ziebell A, Turner GB, Decker SR, Hinchee MAW, et al. Down-regulation of p-coumaroyl quinate/shikimate 3'- hydroxylase (C3'H) and cinnamate 4-hydroxylase $(\mathrm{C} 4 \mathrm{H})$ genes in the lignin biosynthetic pathway of Eucalyptus urophylla $x \mathrm{E}$. grandis leads to improved sugar release. Biotechnol Biofuels. 2015;8(1):128.

33. Cheng SY, Yan JP, Meng XX, Zhang WW, Liao YL, Ye JB, Xu F. Characterization and expression patterns of a cinnamate-4-hydroxylase gene involved in lignin biosynthesis and in response to various stresses and hormonal treatments in ginkgo biloba. Acta Physiol Plant. 2018;40(1):7.

34. Kim J, Choi B, Natarajan S, Bae H. Expression analysis of kenaf cinnamate 4-hydroxylase $(\mathrm{C} 4 \mathrm{H})$ ortholog during developmental and stress responses. Plant Omics. 2013;6(1):65-72.

35. Wei H, Dhanaraj AL, Arora R, Rowland LJ, Fu Y, Sun L. Identification of cold acclimation-responsive Rhodo-dendron genes for lipid metabolism,membrane transport and lignin biosynthesis: importance of moderately abundant ESTs in genomic studies. Plant Cell Environ. 2006;29:558-70.

36. Janská A, Aprile A, Zámečník J, Cattiveli L, Ovesná J. Transcriptional responses of winter barley to cold indicate nucleosome remodelling as a specific feature of crown tissues. Funct Integr Genomics. $2011 ; 11(2): 307-25$.

37. Yuan H, Zhang LC, Jiang Z Y, Wang AD. Characterization of Ripening-Related PuARP4 in Pear (Pyrus ussuri-ensis). J Plant Growth Regul. 2017; 36:766-72.

38. Li XY, Guo W, Li JC, Yue PT, Bu HD, Jiang J, Liu WT, Xu YX, Yuan H, Li T, et al. Histone Acetyla-tion at the Promoter for the Transcription Factor PuWRKY31 Affects Sucrose Accumulation in Pear Fruit. Plant Physiol. 2020; 182:2035-46.

39. Tan DM, Li T, Wang AD. Apple 1-Aminocyclopropane-1-Carboxylic Acid Synthase Genes, MdACS1andMdACS3a, are Expressed in Different Systems of Ethylene Biosynthesis. Plant Mol Biol Rep. 2013; 31(1):204-09.

40. Lee S, Choi J, Kim W, Han T, Park Y, Gemma H. Effect of soil water stress on the development of stone cells in pear (Pyrus pyrifolia,cv.'Niitaka') flesh. Sci Hortic. 2006;110(3):247-53. 
41. Li T, Xu YX, Zhang LC, Ji YL, Tan DM, Yuan H, Wang AD. The Jasmonate-Activated Transcription Factor MdMYC2 Regulates ETHYLENE RESPONSE FACTOR and Ethylene Biosynthetic Genes to Promote Ethylene Biosyn-thesis during Apple Fruit Ripening. Plant Cell. 2017; 29:1316-34.

42. Bu HD, Yu WQ, Yuan H, Yue PT, Wei Y, Wang AD. Endogenous Auxin Content Contributes to Larger Size of Apple Fruit. Front Plant Sci. 2020;11:592540.

\section{Figures}

A

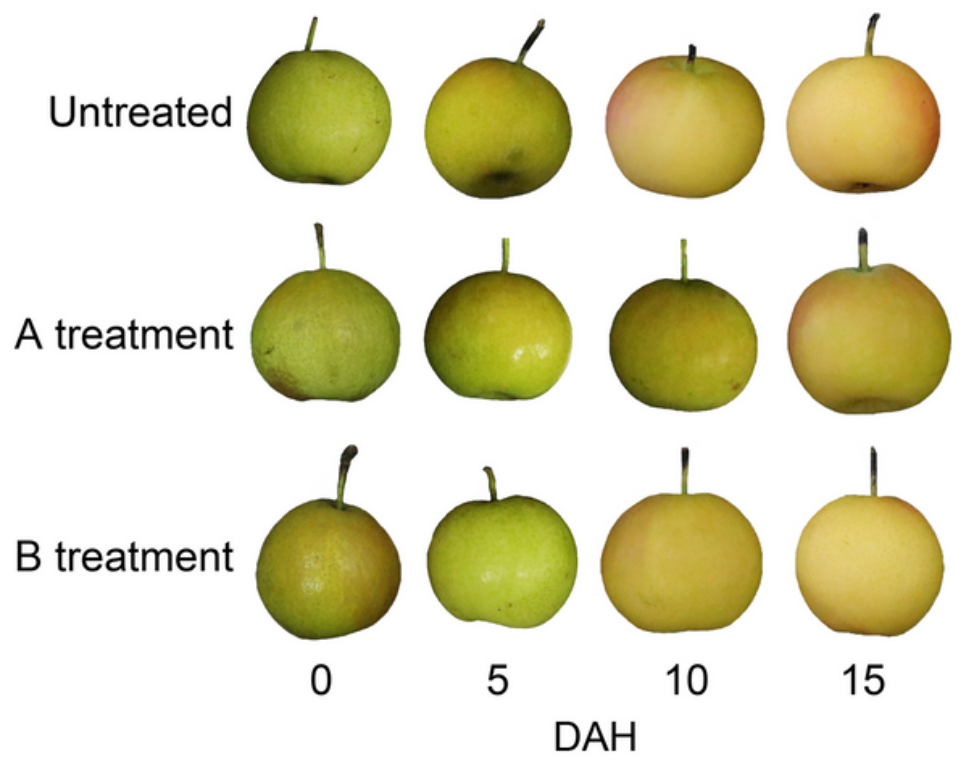

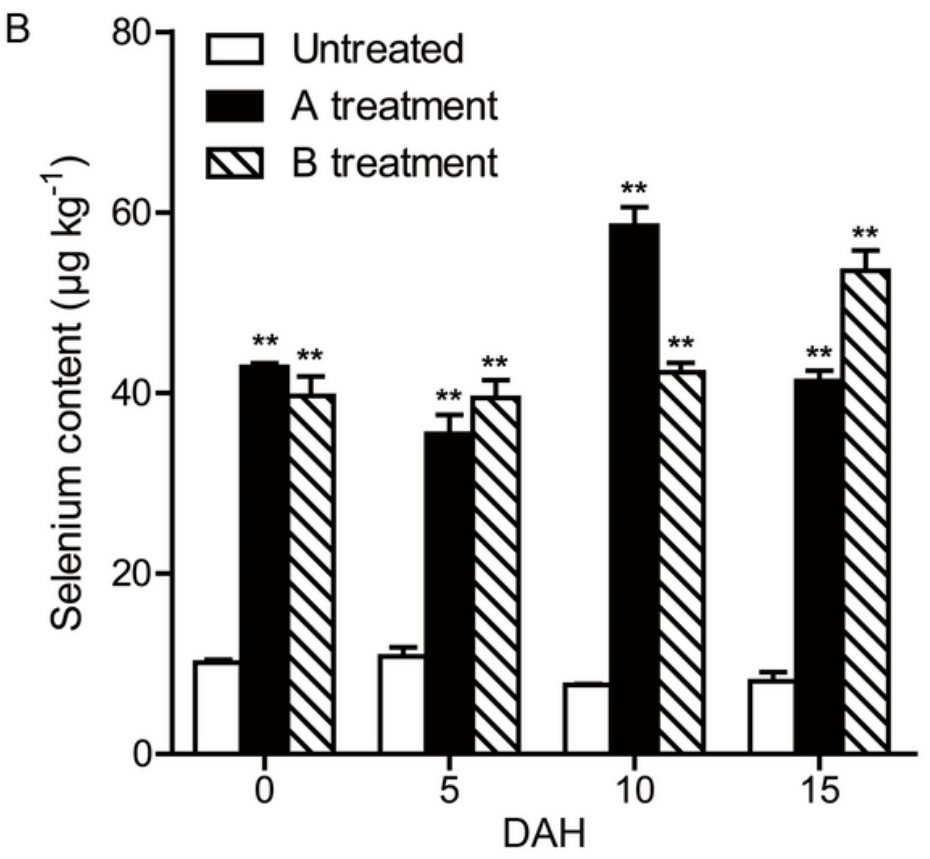

Figure 1

Exogenous Se treatment increased Se content in Nanhong pear fruits Nanhong pear fruits of Se treatment were harvested at $139 \mathrm{DAH}$ (days after harvest), and stored for $15 \mathrm{~d}$ at room temperature (A). Se content of treated fruits was investigated by using ICP-MS (B). ${ }^{*}$ Significant differences $(p<0.01$, Student's t-test). Error bars indicated the standard deviation (SD) of 10 fruits. Bar, $10 \mathrm{~mm}$. 

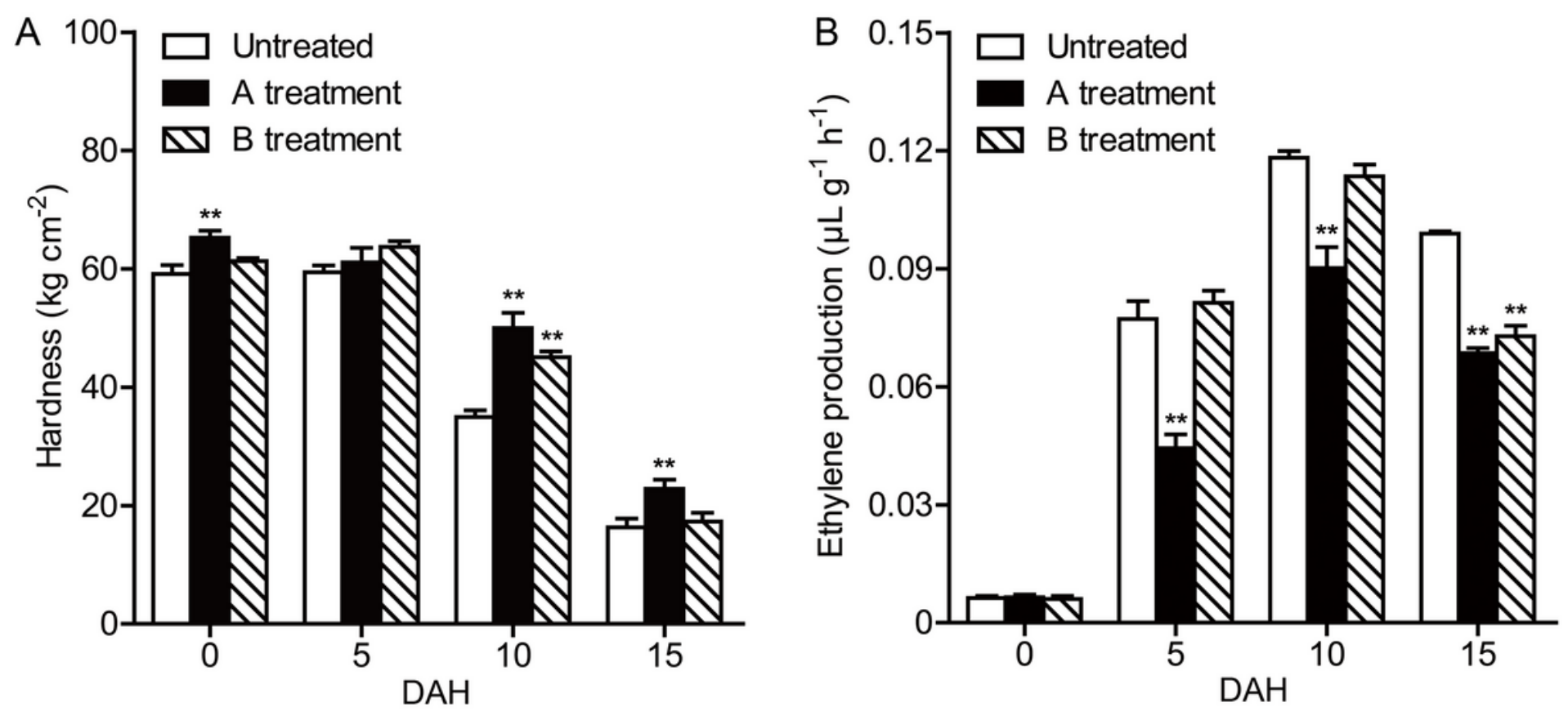

Figure 2

The influencing of the exogenous Se treatment on Nanhong pear fruits during storage. Hardness $(A)$ and ethylene production were measured (B), DAH (days after harvest). ${ }^{*}$ Significant differences $(p<0.01$, Student's t-test). Error bars indicate the standard deviation (SD) of 3 biological replicates. 

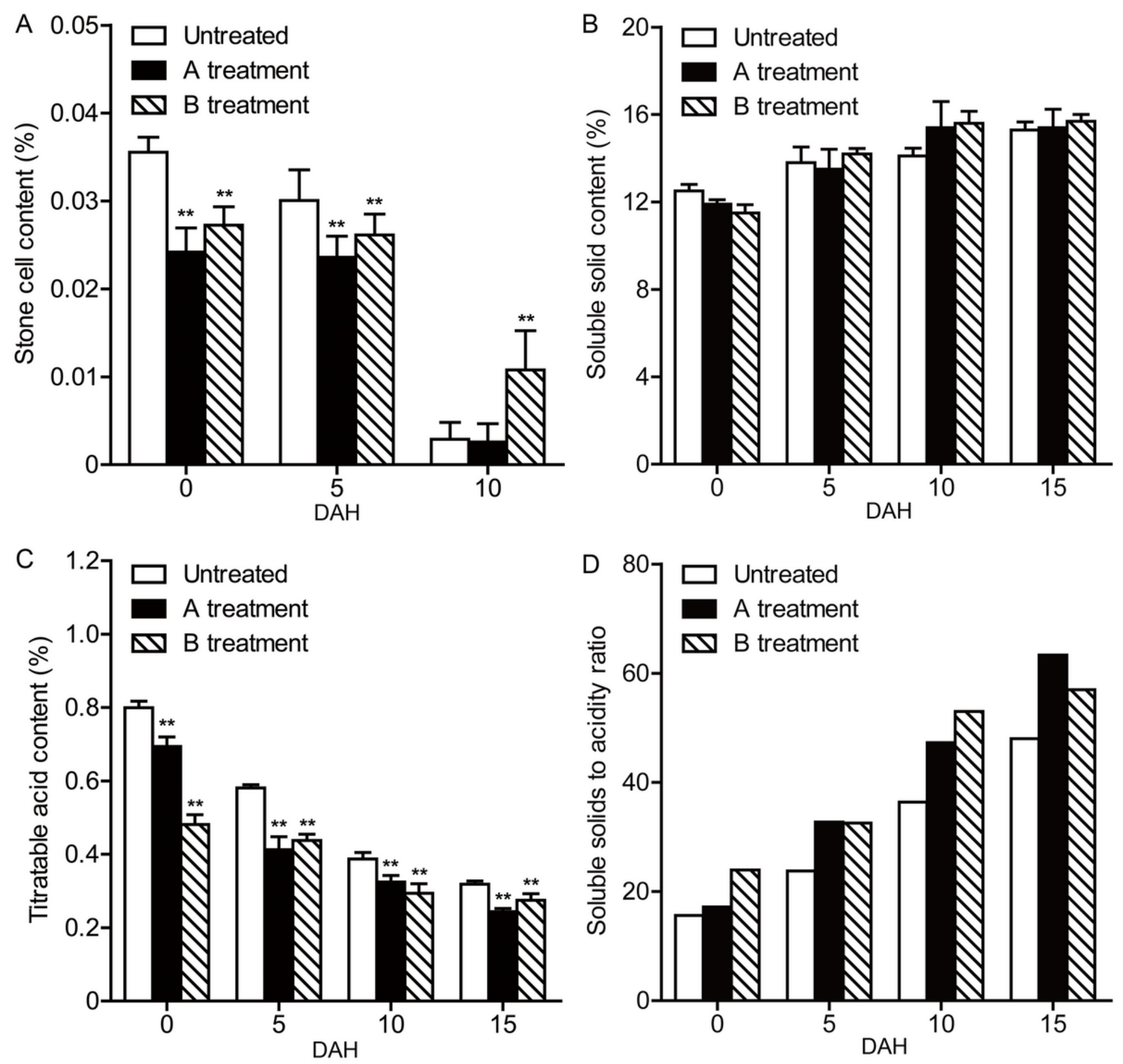

Figure 3

The influencing of Se treatment on Nanhong pear fruits sensory quality during storage. The stone cell content (A), soluble acid content (B) and titratable acid content (C) were measured. Solidity-acid ratio was the ratio of soluble solid to acid (D). DAH (days after harvest). $* \star$ Significant differences $(p<0.01$, Student's t-test). Error bars indicate the standard deviation (SD) of three biological replicates. 

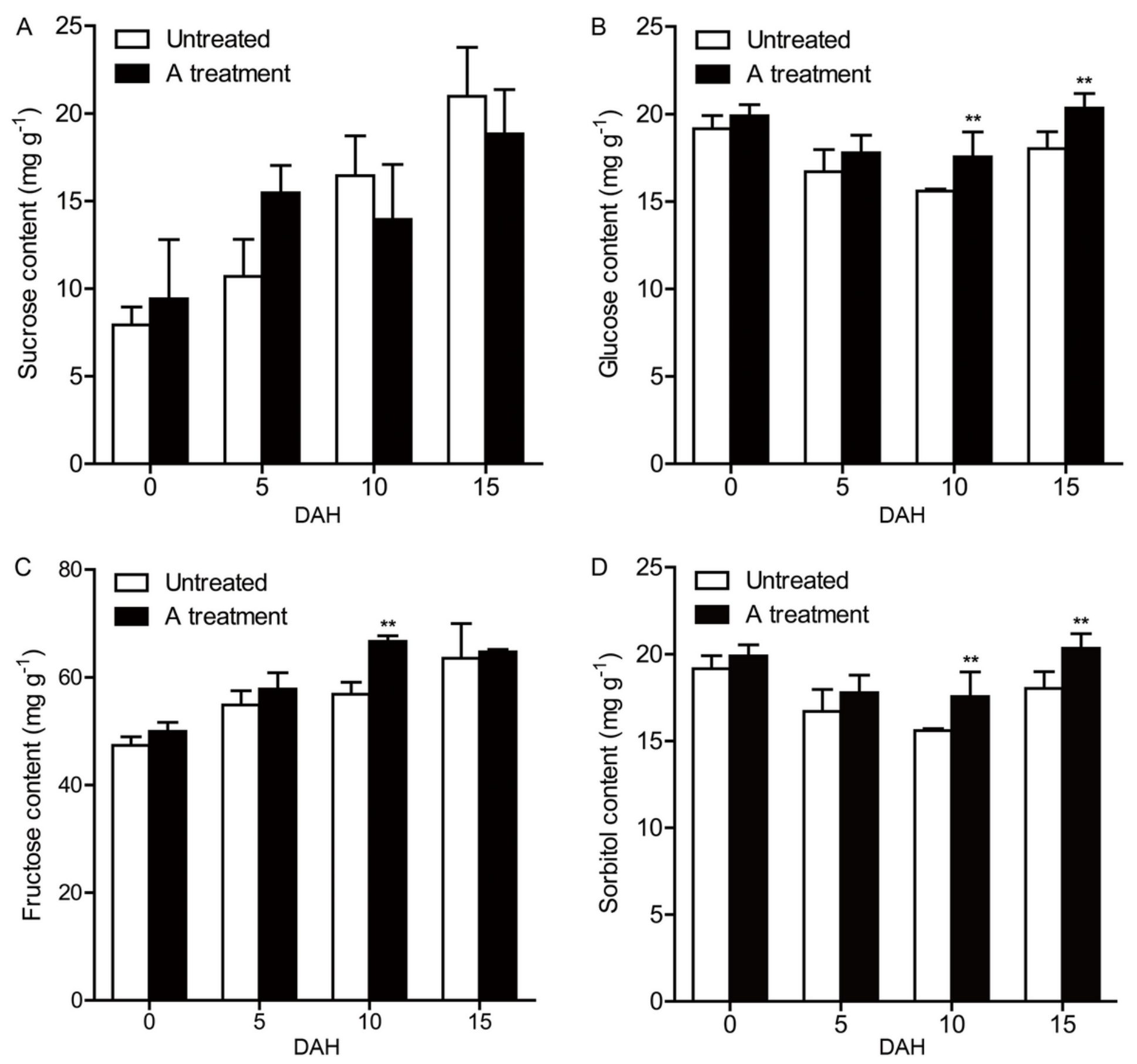

Figure 4

Sugar content of Se treatment of Nanhong pear fruits during storage. Sucrose (A), glucose (B), fructose (C) and sorbitol (D) content were measured using high performance liquid chromatography (HPLC) of Nanhong fruits. Commercial harvest day was 134 DAH (days after harvest). ${ }^{*}$ Significant differences $(p<$ 0.01 , Student's t-test). Error bars indicate the standard deviation (SD) of three biological replicates. 

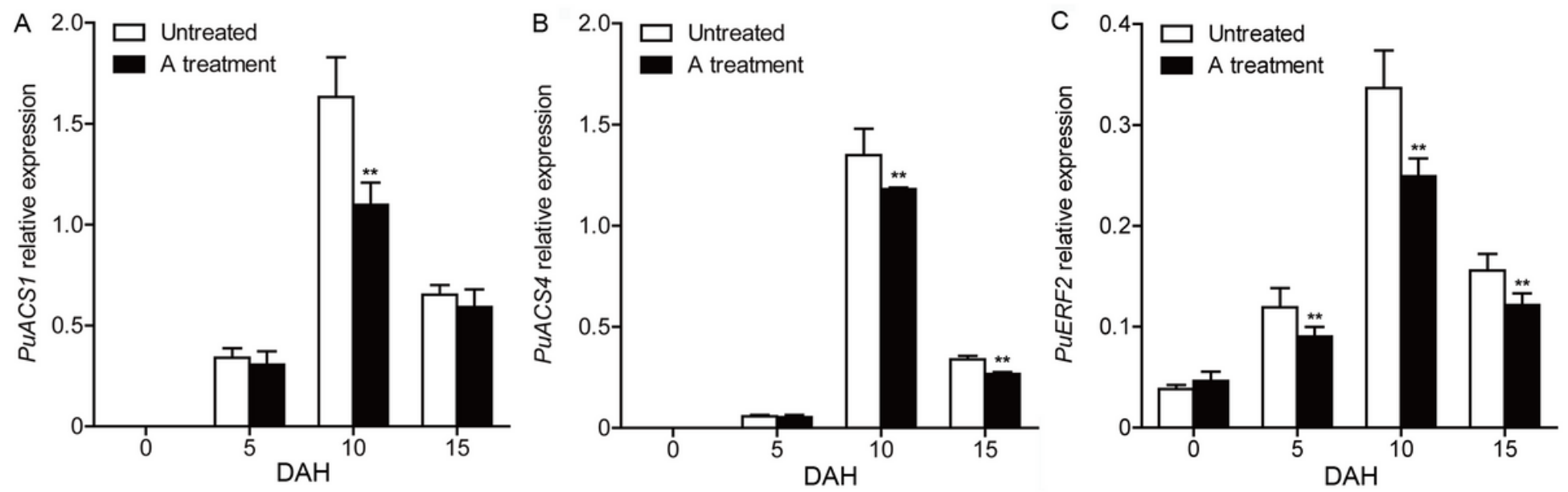

\section{Figure 5}

Se treatment suppressed the expression of ethylene biosynthesis and signal transduction genes. The expression of ethylene biosynthesis genes PuACS1 (A) and PuACS4 (B) were investigated in Nanhong pear fruits. Ethylene signal transduction gene PuERF2 was investigated in Nanhong pear fruits (C). DAH (days after harvest). ${ }^{*}$ Significant differences $(p<0.01$, Student's t-test). Error bars indicate the standard deviation (SD) of three biological replicates.
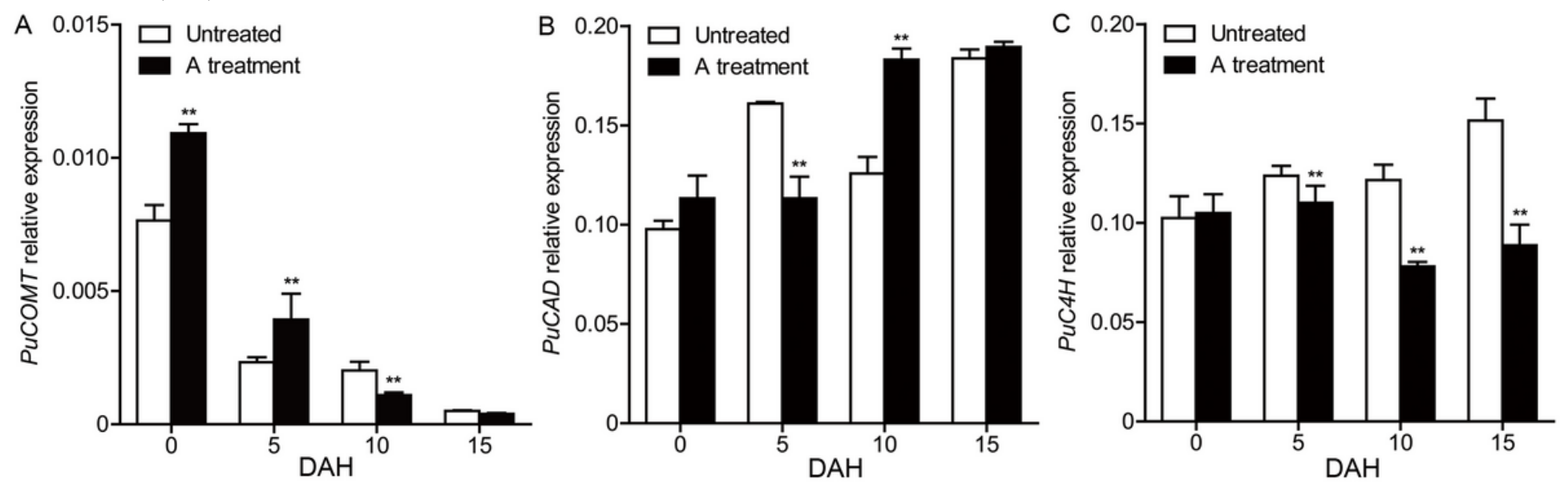

Figure 6

The influence of Se treatment on lignin synthesis genes of Nanhong pear fruits. On-tree Nanhong fruits were treated with Se treatment at on 60,75 and 95 days after flower, respectively, and harvested at 139 DAH (days after harvest). The expression of PuCOMT (A), PuCAD (B) and PuC4H (C) were investigated by qRT-PCR in Untreated and $A$ treatment fruits. ${ }^{*}$ Significant differences $(p<0.01$, Student's t-test). Error bars indicate the standard deviation (SD) of three biological replicates.

\section{Supplementary Files}

This is a list of supplementary files associated with this preprint. Click to download. 
- SupplementalTable1.docx 